Diabetologe 2012 $\cdot 8: 10$

DOI 10.1007/s11428-011-0763-3

Online publiziert: 27. Januar 2012

๑) Springer-Verlag 2012

\section{Herder}

Institut für Klinische Diabetologie, Deutsches Diabetes-Zentrum,

Leibniz-Zentrum für Diabetes-Forschung an der Heinrich-Heine-Universität Düsseldorf

\title{
Molekularbiologie und Genetik in der Diabetesforschung
}

Liebe Leserin, lieber Leser,

„Diabetes: Individualisiert und praktisch handeln" - das war das Motto der fünften Herbsttagung der Deutschen DiabetesGesellschaft im November 2011 in Berlin. Angesichts der Heterogenität der Diabetespatienten und der Tatsache, dass eben nicht alle Menschen mit Diabetes mit den gleichen Therapieoptionen gleich effizient behandelt werden können, gehören nicht nur die Individualisierung der Therapie, sondern bereits im Vorfeld der Erkrankung auch eine individualisierte Prävention zu den aktuell relevantesten Themen in der Diabetesforschung. Um dies $\mathrm{zu}$ erreichen, müssen wir allerdings die Entwicklung des Diabetes besser verstehen. Molekularbiologie und Genetik stellen hier wichtige Methoden und Konzepte zur Verfügung.

In der Untersuchung und Behandlung des Typ-1-Diabetes gibt es eine Reihe von Biomarkern des Stoffwechsels wie z. B. CPeptid, die zu diagnostischen und Forschungszwecken genutzt werden können. Darüber hinaus wird im ersten Beitrag dieses Heftes angesichts der immunmediierten Pathogenese der $\beta$-Zell-Zerstörung auch die Verwendung von Biomarkern des Immunsystems wie Autoantikörper, Zytokine, Chemokine, lösliche Adhäsionsmoleküle und TZellen in Risikoprädiktion, Diagnose und Überwachung der Progression des Typ-1Diabetes diskutiert.

In der Risikoprädiktion des Typ-2-Diabetes werden im Augenblick die klassischen Risikofaktoren Alter, Übergewicht, Dyslipidämie, Familienanamnese des Diabetes und Lebensstilfaktoren wie Ernährung, Bewegung und Rauchen eingesetzt, während die mögliche Bedeutung von neuen Protein-Biomarkern unklar ist. Die Autoren des zweiten Beitrags schlagen im Hinblick auf eine kosteneffiziente Identifizierung von Hochrisikopersonen ein zweistufiges Verfahren vor, das in der ärztlichen Praxis angewendet werden könnte.

\section{\) Biomarkerforschung hat die Individualisierung von Prävention und Therapie des Diabetes zum Ziel}

In den vergangenen 5 Jahren führten neue sog. „Omics-Technologien“ und hypothesenfreie Studienansätze zu signifikanten Fortschritten in unserem Verständnis des Typ-2-Diabetes. Der dritte Beitrag erläutert nicht nur den gegenwärtigen Kenntnisstand zur genetischen Architektur der Erkrankung, sondern zeigt auch die Verbindung neuer Risikogenvarianten mit $\beta$ Zell-Funktion und Insulinfreisetzung auf. Insbesondere von genetischen Varianten erhofft man sich in der Zukunft eine individualisierte Risikovorhersage.

Die Untersuchung von RNA-Genexpressionsprofilen in TranscriptomicsStudien schließt die Lücke zwischen DNA-basierten genetischen Analysen und Analysen von oben angesprochenen Biomarkern auf Proteinebene, die die Produkte vieler zellulärer RNA-Moleküle darstellen. Wie im vierten Beitrag zusammengefasst wird, stehen mit Microarrays und Sequenzierverfahren effiziente Methoden zur Charakterisierung verschiedener Klassen von RNA-Molekülen zur Verfügung, deren Relevanz für die Diabetesforschung in laufenden Studien geprüft wird.

Abschließend werden neue Methoden zur Quantifizierung von Metabolitmustern in Blut und anderen Bioproben beschrieben. Metabolitprofile werden ebenso wie Genexpressionsprofile durch erbliche Faktoren und Umwelteinflüsse bestimmt und können somit als individuelle Abbilder physiologischer und pathophysiologischer Prozesse im Körper betrachtet werden, die ein erhöhtes Diabetesrisiko anzeigen und möglicherweise eine Definition neuer Subtypen des Diabetes erlauben können.

Insgesamt stellen die Übersichten in diesem Heft einen Ausschnitt der Biomarkerforschung dar, die von Partnern des Deutschen Zentrums für Diabetesforschung (DZD) und kooperierenden Instituten durchgeführt wird, um durch Grundlagenund klinische Forschung dem Ziel der Individualisierung von Prävention und Therapie des Diabetes näherzukommen.

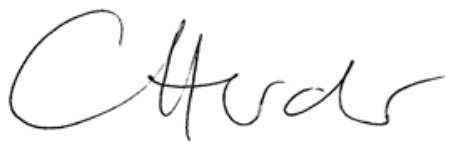

C. Herder

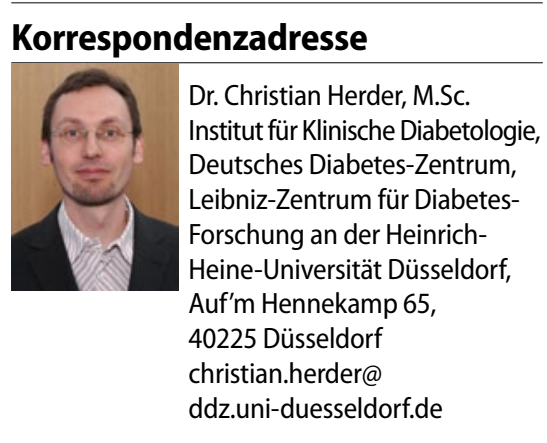

